\title{
Building research initiative group: chronic illness management and adherence in transplantation (BRIGHT) study: study protocol
}

\author{
Lut Berben PhD RN, Kris Denhaerynck PhD RN, Fabienne Dobbels PhD, Sandra \\ Engberg PhD RN, Johan Vanhaecke MD PhD, Maria G. Crespo-Leiro MD PhD, \\ Cynthia L. Russell PhD RN, Sabina De Geest PhD RN, for the BRIGHT study \\ consortium
}

\begin{abstract}
Aim. This article describes the rationale, design and methodology of the Building research initiative group: chronic illness management and adherence in transplantation (BRIGHT) study. This study of heart transplant patients will: (1) describe practice patterns relating to chronic illness management; (2) assess prevalence and variability of nonadherence to the treatment regimen; (3) determine the multi-level factors related to immunosuppressive medication non-adherence.

Background. The unaltered long-term prognosis after heart transplantation underscores an urgent need to identify and improve factors related to survival outcomes. The healthcare system (e.g. level of chronic illness management implemented) and patient self-management are major drivers of outcome improvement.

Design. The study uses a survey design in 40 heart transplant centres covering 11 countries in four continents.

Methods. Theoretical frameworks informed variable selection, which are measured by established and investigatordeveloped instruments. Heart transplant recipients, outpatient clinicians and programme's directors complete a survey. A staged convenience sampling strategy is implemented in heart transplant centres, countries and continents. Depending on the centre's size, a random sample of 25-60 patients is selected ( $\mathrm{N}$ estimated 1680 heart transplant recipients). Five randomly selected clinicians and the medical director from each centre will be invited to participate. Conclusion. This is the first multi-centre, multi-continental study examining healthcare system and heart transplant centres chronic illness management practice patterns and potential correlates of immunosuppressive medication nonadherence. The knowledge gained will inform clinicians, researchers and healthcare policy makers at which level(s) interventions need to be implemented to improve long-term outcomes for transplant recipients.
\end{abstract}

Keywords: chronic illness, health behaviour, healthcare system, medication adherence, nursing, organ transplantation, patient compliance 


\section{Introduction}

Over the past decades, survival rates in heart transplant (HTx) recipients have improved largely due to advances in immunosuppressive medication regimens and better surgical techniques but are limited to the first 12 months post transplantation. Long-term survival remains largely unchanged (Lodhi et al. 2011, Stehlik et al. 2012), indicating the urgent need to identify and improve factors related to long-term survival outcomes. Evidence in other chronically ill patient populations shows that the healthcare system (e.g. level of chronic illness management (CIM)) and patient self-management (e.g. adherence) drive improvements in outcomes (Nuno et al. 2012).

\section{Background}

The level of CIM refers to the extent to which the principles of CIM are implemented in the care of chronically ill patients e.g. HTx recipients who require lifelong medical follow-up and active patient engagement in a variety of health behaviours. These include medication taking, regular physical activity, reducing/stopping alcohol intake, sun protection, non-smoking and keeping medical appointments. Despite their chronic condition, healthcare for this population is commonly organized around an acute, episodic model, typically focuses on detection and treatment of acute illnesses rather than preventive measures and promoting effective self-management. In contrast CIM principles focus on continuity of care; partnerships with patients, families and communities; patient self-management support; attention to preventive measures; decision making support; and use of clinical information systems (Bodenheimer et al. 2002, Yach 2002, Pruitt \& Epping-Jordan 2005, Nolte \& McKee 2008). The Chronic Care Model (CCM), developed by Wagner and colleagues, provides a structure to create or redesign healthcare organizations and systems enhancing their capacity to manage long-term health problems (Bodenheimer et al. 2002). The World Health Organization (WHO) adapted the CCM, adding community and policy aspects to give a global perspective (Epping-Jordan et al. 2004). The Innovative Care for Chronic Conditions (ICCC) framework (Figure 1) proposes that the basis for better outcomes in chronically ill patients lies in forming partnerships between informed, motivated and prepared patients and families; a motivated healthcare team and informed community partners (Yach 2002, Epping-Jordan et al. 2004). This triad is influenced by the healthcare organization, broader community and policy environment. In the ICCC framework healthcare organization building blocks are: promoting continuity and coordination; encouraging quality through leadership and incentives; organizing and equipping healthcare teams; using information systems and supporting self-management and prevention (Yach 2002). Evidence shows that specifically trained nurses (e.g. nurse practitioners, clinical nurse specialists) are key players in the management and coordination of care for chronically ill patients and in improving health outcomes and reducing use of health resources (Busse et al. 2010). 


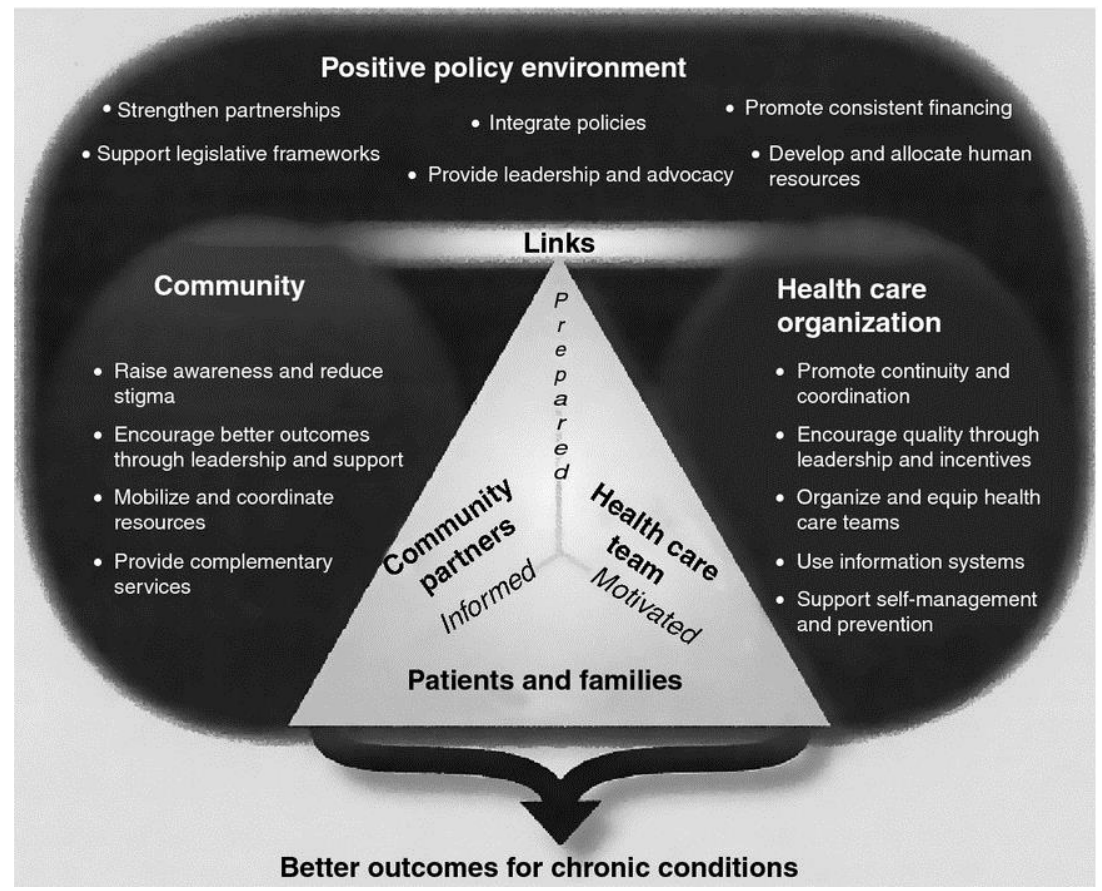

Figure 1 The Innovative Care for Chronic Conditions (ICCC) framework (Yach 2002).

Little information is available on practice patterns relating to CIM in transplant programmes worldwide. Bissonnette et al. (2013) utilized a quasi-experimental design to test a CIM programme based on the CCM (shared decision making, self-management strategies, adherence enhancing interventions and instruction on accessing community resources) in kidney transplantation in Canada. Patients in the intervention group were significantly more likely to reach targeted clinical outcomes, had fewer emergency room visits and hospital admissions and had more discussions about end-stage treatment options relative to the control group, suggesting the value of this model for transplantation (Bissonnette et al. 2013). Evidence from other chronically ill populations shows that care based on the CCM/ICCC framework is more appropriate than the acute care model in preventing or minimizing the frequency and extent of exacerbations and complications (Kane et al. 2005) leading to fewer hospital admissions (Drewes et al. 2012); reduced risk of mortality (Drewes et al. 2012); improved quality-of-life (Coleman et al. 2009, Drewes et al. 2012); health behaviours improvements (e.g. physical activity, dietary habits, medication adherence) (de Bruin et al. 2012, Moullec et al. 2012); reductions in HbA1c, LDL cholesterol and arterial blood pressure (Coleman et al. 2009); and increased patient and caregiver satisfaction (de Bruin et al. 2012). In a systematic review examining the financial impact of the CCM components, more than half of the studies reported healthcare savings (de Bruin et al. 2011). In studies of other chronic illnesses, delivery system redesign and self-management support were found to be the most influential factors (Nuno et al. 2012).

The evidence that self-management support improves outcomes in the chronically ill emphasizes the relevance of patient health behaviours. Non-adherence is defined as the extent to which a person's behaviour in medication taking, following a diet and/or executing lifestyle changes diverges from the agreed on healthcare provider recommendations (Sabaté 2003). Non-adherence to various health behaviours ranges widely between $3 \cdot 2-47 \%$, depending on the measurement methods, operational definitions and sampling methodology. Eleven to $40 \%$ of the HTx patients (about 14.5 cases per 100 patients annually) are non-adherent to their immunosuppressive regimen (De Geest et al. 2005, Dew et al. 2007, 2008, De Bleser et al. 2011) with, consequentially, higher rates of late acute rejections, chronic graft dysfunction, graft loss and mortality risk (Dew et al. 1999, Dobbels et al. 2004, De Geest et al. 
2011). Limited evidence shows rates of non-adherence to co-medications are higher. De Bleser and colleagues found a self-reported co-medication non-adherence rate of 39.2\% in HTx patients (De Bleser et al. 2011), higher than immunosuppressive non-adherence. Between $3 \cdot 2 \%$ and $47.2 \%$ of HTx patients smoke (Nagele et al. 1997, De Geest et al. 2005, Botha et al. 2008, Evangelista et al. 2009), which is associated with higher rates of malignancies, cardio allograft vasculopathy and mortality (Goldstein et al. 1996, Curtil et al. 1997, Nagele et al. 1997, Botha et al. 2008). Almost five HTx recipients per 100 annually are non-adherent to recommendations to limit/quit alcohol use (Dew et al. 2007). Although the differences were not statistically significant, Owen et al. found that current or recent alcohol dependence increased the risk of post-HTx hospitalization, infections and death (Owen et al. 2006). Non-adherence to physical activity is prevalent with an estimated rate of 33.7 cases per 100 HTx annually (Dew et al. 2007). Interventions encouraging higher levels of physical activity have been associated with improved outcomes including reductions in blood pressure, decreased hyperlipidaemia, increases in peak $\mathrm{VO}_{2}$ and better quality-of-life (Schmidt et al. 2002, Braith et al. 2008, Hermann et al. 2011). Dietary nonadherence ranges between 16-41.5\% (De Geest et al. 2005), or 28.1 cases per 100 recipients annually (Dew et al. 2007). In the general population, non-adherence to a prescribed diet (e.g. low sugar/salt/fat) is associated with an increased risk for development and progression of hypertension, diabetes and obesity (Lopez et al. 2008, Zhao et al. 2011). Non-adherence to appointment keeping in HTx recipients ranges between 3-26.4\% (Dew et al. 1996, De Geest et al. 2000, 2005) or 8.5 cases per 100 HTx patients annually (Dew et al. 2007), and has been associated with an increased risk in late acute rejections (De Geest et al. 2000). No information on the prevalence of non-adherence to sun protection measures is available in HTx. Organ transplant recipients, however, are at higher risks of developing skin cancer due to the effects of long-term drug-induced immunosuppression (Feuerstein \& Geller 2008, Zwald et al. 2010).

To improve patient's adherence to the treatment regimen, it is crucial to target interventions for modifiable factors influencing behaviour (Berben et al. 2012). The WHO identified five dimensions that determine medication adherence: (1) patient-related factors (e.g. self-efficacy and beliefs about the efficacy of treatment); (2) social and economic factors (e.g. literacy, level of education and social support); (3) therapy-related factors (e.g. duration of treatment and dose complexity); (4) conditionrelated factors (e.g. comorbidities and depression); and (5) healthcare system and team-related factors (e.g. trust in the healthcare team, level of CIM implemented). To-date, most research on adherence has focused on medication non-adherence. In these studies patient, socio-economic, therapy and conditionrelated risk factors were examined in an attempt to explain the high rates of non-adherence (Kidd \& Altman 2000, Sabaté 2003). However, as a meta-analysis in transplantation demonstrated, this group of risk factors accounts for a small portion of the observed variability (Dew et al. 2007) suggesting the need for more emphasis on healthcare system and healthcare team related risk factors.

An expert panel on adherence of the American Heart Association recommended integrating strategies at the patient, provider and an organization level to optimize adherence management (Miller et al. 1997). The US Agency for Healthcare Research and Quality (Viswanathan et al. 2012a) concluded that adherence is a complex behaviour with multiple determinants. Clinical practice guidelines from the National Institute for Health and Clinical Excellence (NICE) (Nunes et al. 2009) strongly emphasize use of a systems approach in managing medication adherence. In 2010 the American Society of Hypertension recommended an ecological approach to increase patient adherence to anti-hypertensive medications (Hill et al. 2010). It is not clear from previous studies which factors at which level(s) contribute to nonadherence. In their review, Viswanathan and colleagues concluded that additional research is needed to identify the specific multi-level factors that most influence adherence (Viswanathan et al. 2012b).

The BRIGHT study addresses these gaps in the literature by examining the extent to which HTx centres' practice patterns reflect the ICCC model and the relationship between the level of CIM implemented and adherence to immunosuppressive medications. By collecting data on patient, healthcare provider, healthcare organization and healthcare system and policy-level factors, a multi-level approach will be used to examine the interrelating impact of individual factors and whether the combined effects of risk factors associated with immunosuppressive medication non-adherence are additive or synergistic. The participation of centres in multiple countries and continents will give us the unique opportunity to 
benchmark CIM practice patterns, and patient non-adherence relating to various aspects of the treatment regimen within and between countries and continents.

\section{The study}

\section{Aims}

The primary aims of this study are:

1. To describe CIM practice patterns among centres, countries/continents in HTx.

2. To assess the prevalence and variability of non-adherence to treatment regimen, i.e. medication taking, smoking cessation, diet keeping, alcohol consumption, physical activity, sun protection and appointment keeping in HTx recipients among centres, countries/continents.

3. To determine which multi-level factors are related to immunosuppressive medication adherence at the:

- Patient level: i.e. patient beliefs, intentions, self-efficacy and barriers, confidence in immunosuppressive medication taking, depression, health literacy

- Healthcare provider level: i.e. patient satisfaction with the interpersonal dimension of care, trust in the transplant team, received social support

- Healthcare organization level: i.e. CIM transplant programme practice patterns

- Healthcare system and policy level: i.e. perceived financial burden of the treatment regimen, insurance status, system of healthcare coverage, country.

4. To benchmark participating centres, countries and continents in relation to CIM practice patterns and non-adherence to health behaviours.

\section{Conceptual framework}

The ecological model integrates healthcare system factors in explaining patient behaviour. It identifies factors at the patient, healthcare provider, healthcare organization and healthcare system and policy levels as important correlates of patient behaviours and provides a framework for assessing the extent to which components of the chronic illness model are incorporated in clinical settings.

\section{Design/methodology}

The BRIGHT study is an international multi-centre, cross-sectional study using a survey design. This study is managed by a project team consisting of the principle investigator, co-investigators and project manager. The BRIGHT consortium, consisting of experts in organ transplantation from different disciplines and countries, serve as an advisory body for the project team which participate in bi-weekly telephone conferences to discuss study progress. In addition, bi-monthly telephone conferences are scheduled with all members of the BRIGHT consortium. This study is endorsed by several professional transplant and patient organizations.

\section{Sample/participants}

The BRIGHT study uses a multi-staged sampling approach. A convenience sample of countries and HTx centres is recruited followed by a randomized sampling procedure for patients and clinicians. Countries included are: Australia; Belgium; Brazil; Canada; France; Germany; Italy; Spain; Switzerland; the UK; and the US. To be eligible, a country had to have at least two eligible HTx centres. 
HTx centres are invited to participate using the network of the International Transplant Nurses Society (ITNS), the International Society of Heart and Lung Transplantation (ISHLT) and contacts of the BRIGHT team members. HTx centres are eligible to participate in the study if: (1) $\geq 50$ HTx have been performed during the 12-60 months prior to inclusion (i.e. about 10 transplant procedures annually); (2) the centre is located in Europe (Belgium, France, Germany, Italy, Spain, Switzerland or the UK); North America (Canada or the US); South America (Brazil) or Australia; and (3) the study is formally supported by the centre's transplant director and responsible administrator.

In each centre, HTx clinicians are recruited using the following inclusion criteria: (1) worked in the centre $>6$ months; (2) employed $\geq 50 \%$ in direct clinical practice; and (3) familiar with the posttransplant outpatient care at the centre. Based on the number of eligible clinicians, we use a convenience (if $\leq 5$ clinicians are eligible, all are included) or a random (if $>5$ clinicians are eligible a random sample of 5 are selected) sample.

HTx recipients are selected using a proportionate cluster randomized sampling strategy. Inclusion criteria for the patient are: (1) HTx recipient; (2) $\geq 18$ years of age at time of inclusion; (3) transplanted and followed up for routine care in a participating transplant centre; (4) first transplant; (5) single-organ transplant; (6) between 1-5 years posttransplant; (7) ability to read, understand and give a signature on an informed consent (in Dutch, English, French, German, Spanish, Italian, or Brazilian Portuguese, depending on the languages spoken in the country of the participating transplant centre); and (8) give written informed consent. Patients are excluded if they: (1) participated in adherence-intervention research or drug trials during the past 6 months (participation in previous descriptive research is allowed); or (2) currently receive professional support in taking their medications.

The sampling strategy is guided by known variability in the size of the centres relative to the number of transplant recipients in follow-up and the number of yearly transplantations performed. Centres are therefore categorized into three groups based on the ISHLT criteria (International Society of Heart \& Lung Transplantation 2011). Based on the 5-year data, centres performing 50-74 HTx are classified as small, those performing 75-100 HTx as medium and those performing >100 HTx as large. A power analysis showed that a modest association (i.e. an odds ratio of 1.25) between adherence and the level of CIM implemented should be detectable with at least 28 patients per centre, assuming at least 40 centres and a power of $90 \%$. With an estimated participation rate of $70 \%$, on average, 40 patients per centre need to be invited to participate. This sample size will be obtained by including 40 centres and 25/40/60 patients per centre respectively for small/medium/large size centres, reaching a total predicted sample size of 1680 HTx patients.

\section{Theoretical framework used to select variables}

Two theoretical frameworks combined with evidence from the literature were used to select the potential correlates of immunosuppressive medication non-adherence: the Integrative Model of Behavioral Prediction (IMBP) (Figure 2) (Fishbein et al. 2003) for variables at the patient level and the ecological model (Figure 3) (Bronfenbrenner 1980, Berben et al. 2012) for healthcare system-related variables. The IMBP describes behaviour as dependent on intentions and determinants of intentions are attitudes, norms and self-efficacy. Although intention is the primary determinant of behaviour, lack of skills and abilities and environmental constraints or barriers may prevent a person from acting on his/her intentions (Fishbein et al. 2003). The ecological model takes the influence of multiple levels of the healthcare system into account in explaining behaviour. These are: the patient, healthcare provider level (i.e. factors related to social support and interpersonal or face-to-face relationships with healthcare professionals (Yach 2002)), the healthcare organization level (i.e. characteristics of the healthcare organization where the patient is treated (Yach 2002)) and the healthcare system and policy level (i.e. the characteristics of the healthcare system where a patient lives (Yach 2002, Berben et al. 2012)). 


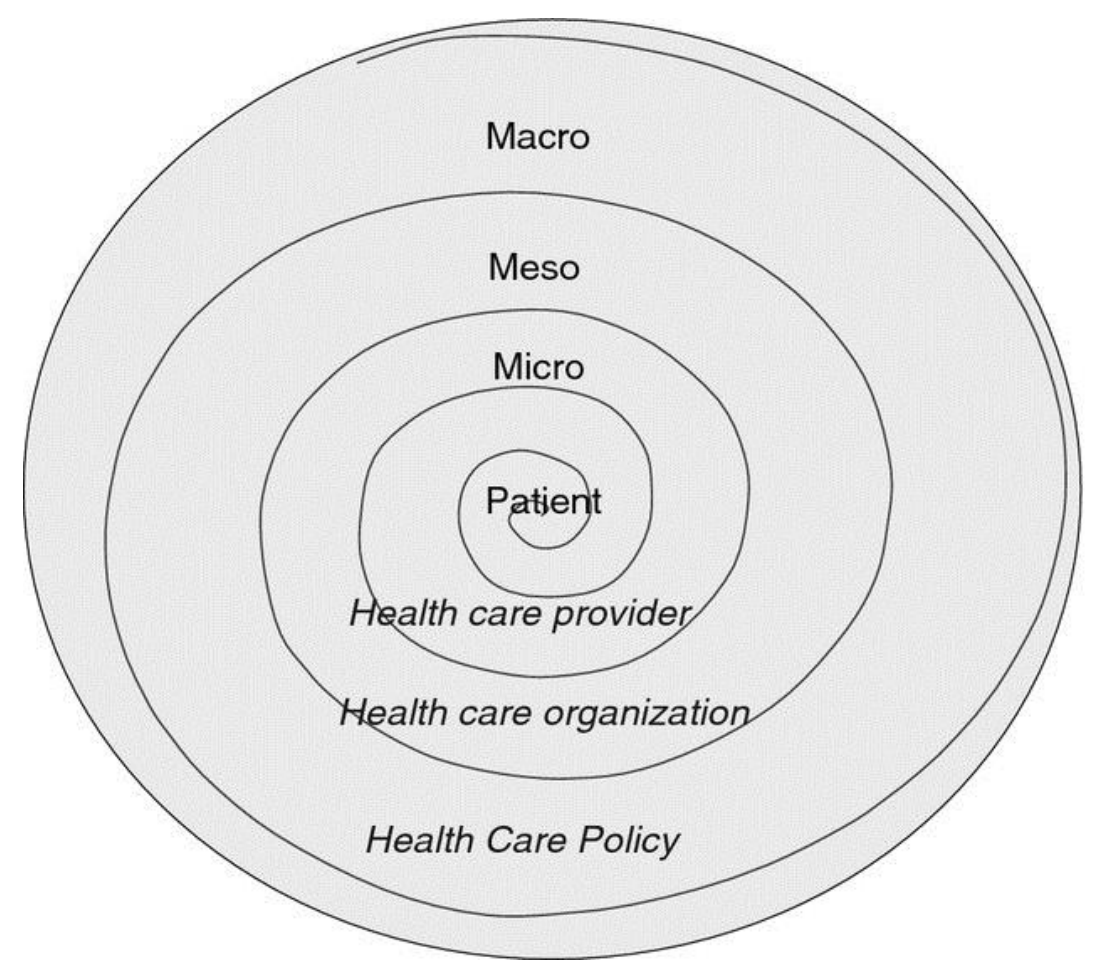

Figure 2 The ecological model of Bronfenbrenner et al. (Bronfenbrenner 1977, 1980) (adapted).

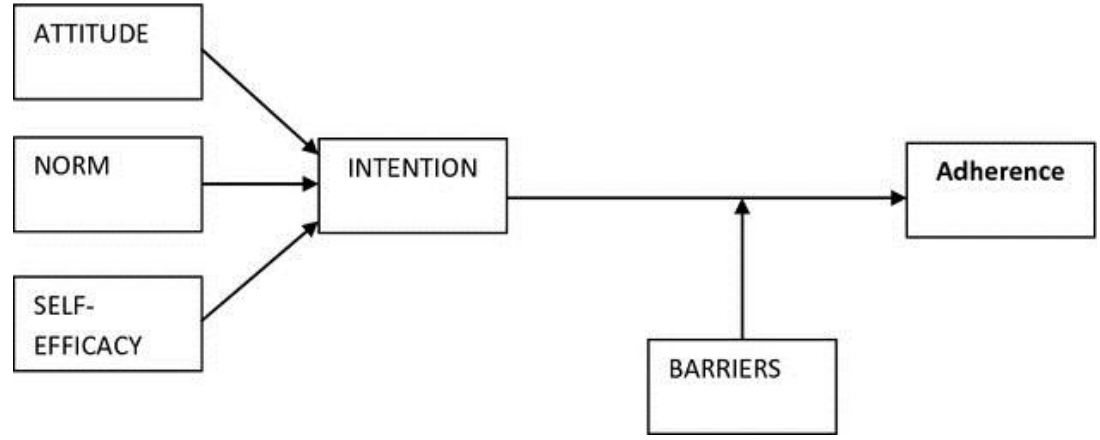

Figure 3 Patient level: Modified Integrative Model of Behavioral Prediction (Fishbein et al. 2003, Schmid-Mohler et al. 2010)

Variables are measured using established instruments or investigator-developed measures. The instruments are described in detail in (Tables S1-S6). CIM practice patterns are collected from patients, clinicians and transplant centre directors using self-report questionnaires. Methods of patient data collection include an interview, self-report questionnaires, medical chart review and collateral reports by nurses and physicians. The methodology in this study is based on the results of several pilot studies (Schmid-Mohler et al. 2010, Ducci et al. 2013). The questionnaire assessing practice patterns, completed by centres' transplant clinicians and directors, was pilot tested in two centres in the USA and in one centre in the UK and required only minor editorial adaptations. The patient questionnaires were pilot tested with a sample of 58 HTx recipients in Belgium and adapted for 268 liver transplant recipients in Italy (Ducci et al. 2013) and 114 kidney transplant recipients in Switzerland (Schmid-Mohler et al. 2010). 
All instruments used in the BRIGHT study were translated in a culturally sensitive way using the Wild protocol (Wild et al. 2005). The instruments are available in English, Dutch, French, German, Italian, Spanish and Brazilian Portuguese.

\section{CIM practice patterns}

The Chronic Illness Management Implementation - Building Research Initiative Group: Chronic Illness Management and Adherence in Transplantation (CIMI-BRIGHT) instrument was developed to assess clinicians' perceptions practice patterns related to CIM (Table S1), the development was based on the ICCC framework (Figure 1), a review of the CIM literature and the clinical expertise of the research transplantation team (Berben et al. 2014). The instrument passed several validation rounds. Patients' perceptions of CIM practice patterns are assessed by the short version of the Patient Assessment of Chronic Illness Care instrument (Gugiu et al. 2009) (Table S1).

\section{Behavioural factors}

Non-adherence to immunosuppressive medication is assessed by interview using a validated selfreport measurement, the Basel Assessment of Adherence with Immunosuppressive Medication Scale ${ }^{\odot}$ (BAASIS) (Dobbels et al. 2010, Marsicano Ede et al. 2013) and by the collateral reports of nurses and physicians (Table S1) (De Bleser et al. 2011). Non-adherence to other medications (excluding immunosuppressive medications) is assessed using an adapted version of the BAASIS ${ }^{\odot}$ (Dobbels et al. 2010, Marsicano Ede et al. 2013) (Table S2). The current level of physical activity is assessed using the Brief Physical Activity Assessment Tool (Marshall et al. 2005) (Table S2). Current and former smoking status is assessed using an item from the Swiss Health Survey (Swiss Federal Statistical Office 2008) (Table S2). Investigator-developed questions assess current alcohol use, non-adherence to dietary modifications and appointment keeping (Table S2). Sun protection behaviour is assessed using a combination of items used in the Swiss Childhood Cancer Registry (Swiss Childhood Cancer Registry) and the Cambridge University Hospitals' Perception of Skin Cancer in Transplant Recipients scale (Haque Hussain et al. 2011) (Table S2).

\section{Correlates of immunosuppressive medication non-adherence}

Patient level. Based on the IMBP (Figure 3) (Fishbein et al. 2003), correlates of non-adherence to immunosuppressive medications assessed at the patient level are (Table S3) attitudes towards immunosuppressive medication intake (investigator-developed questions), normative beliefs related to immunosuppressive medications (investigator-developed questions based on previous transplant literature (Greenstein \& Siegal 1998, Gifford et al. 2000, Russell et al. 2003, Butler et al. 2004, Chisholm et al. 2007, Denhaerynck et al. 2007)), medication taking self-efficacy (Long-Term Medication Behavior SelfEfficacy Scale (Denhaerynck et al. 2003)), intentions to adhere to immunosuppressive medications (investigator-developed question), barriers in taking immunosuppressive medications as prescribed (Immunosuppressive Medication Adherence Barriers scale (The Transplant360 Task Force)), sleep quality (item from the Kidney Disease and Quality of Life Short Form (Hays et al. 1997)), daytime sleepiness (item adapted from the Dialysis Outcomes and Practice Patterns Study (Elder et al. 2008) and a VAS Sleepiness Scale (Zallek et al. 2008)), depression (depression items of the Depression, Anxiety, Stress Scale 21-item version (Gloster et al. 2008)) and health literacy (screening questions of Peterson et al. (Peterson et al. 2011)), co-morbidities (adapted version of the Charlson co-morbidity index (Fried et al. 2001)), readiness to change immunosuppressive medication taking (investigator-developed question). Demographic data on the patient is also collected. The date of the HTx, history of diabetes pretransplant, aetiology of heart failure, the patient's height and weight and the number of treated rejections are retrieved by medical chart review. 
Healthcare provider level. Factors assessed by patient self-report (Table S4): patient satisfaction with the interpersonal dimension of care (part 1 of the Westaway Patient Satisfaction scale (Westaway et al. 2003)), trust in the transplant team (Wake Forest University Trust Scale (Hall et al. 2002)) and received social support (Social Support Questionnaire (Dobbels et al. 2005)).

Healthcare organization level. As well as CIM practice patterns, the core competencies of the transplant team in chronically ill patient care, including the presence and role of advanced practice nurses are collected by clinicians self-report. Characteristics of the transplant centre are assessed by transplant director self-report. Self-report demographic information is collected from transplant clinicians (Table S5).

Healthcare system and policy level. Insurance status and perceived treatment-related financial burden are assessed by patient self-report (Table S6) using items from the Supporting Medication Adherence in Renal Transplantation Study questionnaire (Denhaerynck et al. 2007). Cost related non-adherence is assessed by questions used by Wilson et al. (2007) (Table S6). Country specific data such as the type of healthcare system, expenditure on health, the density of nurses and physicians per 1000 inhabitants, the number of acute beds per 1000 inhabitants and chronic disease mortality rates are retrieved from the Organization for Economic Cooperation and Development (OECD) and the Commonwealth Fund statistical databases (Table S6). Transplant relevant aggregated country-level data (e.g. number of HTx centres and number of HTx performed) are retrieved from the ISHLT data bases (Table S6).

\section{Data collection}

Data collection is coordinated and led by the Institute of Nursing Science, University of Basel, Switzerland. There are four study phases:

1. Obtaining local IRB approval: Once a centre agrees to participate in the study, the project manager works with centre personnel to submit the IRB proposal based on local IRB guidelines.

2. Training of data collectors: Initially they receive a detailed step by step training manual which is followed up by training in their native language via telephone or podcast with backup advice available from the BRIGHT study team members by email, phone or Skype as required.

3. Screening of patients: As soon as IRB approval is received transplant centres are asked to screen all patients for inclusion and exclusion criteria and send a coded list of eligible patients to the investigators who randomly select a sample, using a computational random number generator.

4. Data collection: Questionnaire packages are prepared at the Institute of Nursing Science, University of Basel, Switzerland. At each centre, data are collected from the selected patients, clinicians and the HTx director.

Data collection patient: The purpose of the study is explained to patients during a scheduled outpatient visit, they are invited to participate in the study and informed consent is obtained. The BAASIS patient interview (Dobbels et al. 2010) is conducted and demographic data are collected by interview. Patients receive the patient-administered BRIGHT questionnaire to complete during the outpatient clinic visit. The data collectors collect clinical data from the patient's medical record and ask the nurse and physician to complete the collateral report assessing adherence to immunosuppressive medications. Data collection HTx director: The director completes the transplant centre director questionnaire. Data collection HTx clinicians: The data collector informs the eligible transplant clinicians about the study and, if needed (depending on the IRB requirements for the specific centre), obtains informed consent and forwards the questionnaire. The clinician places the completed questionnaire in the provided envelope and to seal and return it to the data collector. Once data collection is finished, the data collector sends all questionnaires back to the data management centre (Institute of Nursing Science, University of Basel, Switzerland). 
Data collection for this study started on 28 March 2012 and is ongoing. We anticipate completion by autumn 2014. As they completed data collection, each transplant centre receives an intermediate report summarizing adherence data for their specific centre. Following completion of the entire study, all centres will receive a benchmarking report where they will be able to anonymously compare their performance with other centres. The report will be formatted to allow each centre to identify themselves but not other centres.

\section{Data analysis}

Aim 1 \& 2: Descriptive analysis will apply appropriate statistics, including measures of location (e.g. frequencies, means and percentiles) and dispersion (e.g. standard deviations and IQR) for the total sample and by country and centre depending on the level of measurement and data distribution. Data will be summarized in tables and figures.

Aim 3: Exploration of the relationship between immunosuppressive medication non-adherence and its possible correlates at the different levels will be performed using generalized linear mixed regression analysis. This approach is suited to multi-level data in that it disentangles overall error into its nested components (i.e. individual patients in centres in countries), thus providing stronger evidence for the unique association of tested risk factors with non-adherence. It also allows estimation of the proportion of variability at the higher levels that remains unexplained by the variables included and allows testing of interactions across levels.

Aim 4: A detailed descriptive analysis will be performed using the appropriate statistics for all practice patterns and system level factor variables identified as significantly associated with adherence to immunosuppressive medications. Findings will be summarized in tables and figures for each centre.

Software packages used for statistical analysis are IBM Statistics (SPSS, IBM Schweiz AG, Vulkanstrasse 106, CH-8010 Zurich, Switzerland) and SAS (SAS Institute AG, Richtistrasse 11, CH8304 Wallisellen, Switzerland) A $P$ value of $<0.05$ will be considered as statistically significant. The presence of missing data will be mapped and its influence on the results of the modelling explored using sensitivity analyses under different possible scenarios.

\section{Ethical considerations}

Ethical approval is obtained from each participating centres' IRB/ethics committee prior to data collection. The patient information and informed consent forms comply with the guidelines of the Declaration of Helsinki (World Medical Organization 1996) and specific national legislation (e.g. consideration of Health Insurance Portability and Accountability Act in the US). All participants are informed in writing and orally about the aims of the study, why they are selected, what their involvement means in terms of data collection, the risks/benefits of taking part and who the contact persons are for the study. They are also informed that they have the right to discontinue their participation at any time without affecting their treatment by the transplant team or hospital. Safeguards to ensure participant confidentiality are explained and written informed consent is obtained from each participant prior to data collection. 


\section{Validity and reliability}

Several steps are taken to assure the validity and reliability of this study:

First, use of consistent methodology across all centres makes comparisons across centres, countries and continents possible. Second, measurements employed in this study have been used in other studies. Instruments developed for the purposes of this and other studies were tested for validity and reliability using data from the pilot studies or will be tested using data from this current study. Third, a power analysis determined the sample size needed to detect a modest association between adherence and the level of chronic illness management implemented in the centres. Fourth a proportional randomized sampling strategy was used to select patients. Finally, confounding variables will be controlled for by entering them as co-variables in the analysis.

\section{Discussion}

To the best of our knowledge, this is the first multi-centre, multi-continental study assessing practice patterns for CIM in HTx programmes. It is the first study assessing patient non-adherence to different aspects of a treatment regimen (medication intake, smoking cessation, diet keeping, limited alcohol consumption, increase physical activity, sun protection and appointment keeping) in a large sample of HTx recipients across a variety of settings. The consistent methodology in all centres will ensure effective comparison of the prevalence of non-adherence between centres, countries and continents. The sampling methodology, recruitment of multiple centres in countries and across continents and the random selection of patients in centres, will increase the generalizability of the BRIGHT study findings. The BRIGHT study will also examine associations between several selected factors at the patient, healthcare provider, healthcare organization and healthcare system and policy levels and immunosuppressive medication nonadherence. Inclusion of factors at all levels of the healthcare system will allow us to examine their individual contribution and their combined and/or synergistic effect on immunosuppressive medication non-adherence. As the first study of its type, the BRIGHT study results will give a basis for identifying factors which can be targeted in future intervention studies. The results of this study also have potential implications for clinical practice. The feedback that individual centres will receive about patient specific behavioural outcomes (i.e. non-adherence) can be addressed through practice improvement initiatives. Nurses play a key role in outpatient transplant care and in promoting patient self-management behaviours and can use the findings of this study to initiate practice changes designed to improve the care of their chronically ill heart transplant recipients.

\section{Limitations}

A limitation of this large 40 centre survey is not using electronic monitoring to assess one of the study's key variables, immunosuppressive medication non-adherence. This is generally considered the most accurate assessment method (Osterberg \& Blaschke 2005). However, it is very costly and given the size of this study, not feasible. As recommended by Osterberg and Blaschke (Osterberg \& Blaschke 2005) we are using a combination of other assessment methods (i.e. patient self-report and collateral report from the treating nurse/clinician and the treating physician) to measure adherence to immunosuppressive medications. Additionally, the cross-sectional study design does not allow us to make causal inferences. Behaviour might be dynamic and a one point assessment might not entirely reflect health behaviour issues in this patient population. 


\section{Conclusion}

The BRIGHT study is a cross-sectional study assessing CIM practice patterns, non-adherence to various aspects of the treatment regimen and multi-level correlates of immunosuppressive medication regimen in $1680 \mathrm{HTx}$ recipients in $40 \mathrm{HTx}$ centres in 11 countries on 4 continents. Data are also collected from HTx clinicians and the medical director of the HTx programme. Knowledge gained in this study will inform clinicians, researchers and healthcare policy makers at which level interventions to improve immunosuppressive medication adherence must be implemented to improve long-term outcomes for HTx patients.

\section{Acknowledgements}

We wholeheartedly thank all the participating patients, clinicians and the transplant directors for their participation in the BRIGHT study. Furthermore, we want to express our gratitude to the data collectors for all their efforts in preparing the IRB submission and collecting the data.

\section{Funding}

The BRIGHT study is funded by internal budget of the Institute of Nursing Science, University of Basel (Switzerland), research grants of the International Transplant Nurses Society (ITNS) in 2008, the International Society for Heart and Lung Transplantation (ISHLT) in 2012, the Swiss Academy of Medical Sciences (SAMW) in 2013 as well as an unrestricted research grant from Astellas Pharma. None of the grants has a grant number. None of the organizations that provided funding has access to the data nor were involved in the preparation of the manuscript.

\section{Conflict of interest}

The authors declare no conflict of interest.

\section{Author contributions}

All authors have agreed on the final version and meet at least one of the following criteria [recommended by the ICMJE (http://www.icmje.org/ethical_1author.html)]:

- $\quad$ substantial contributions to conception and design, acquisition of data, or analysis and interpretation of data;

- drafting the article or revising it critically for important intellectual content. 


\section{References}

Berben, L., Dobbels, F., Engberg, S., Hill, M.N. \& Geest, S.D. ( 2012) An ecological perspective on medication adherence. Western Journal of Nursing Research 34(5), 635- 653.

Berben, L., Russell, C.L., Engberg, S., Dobbels, F. \& De Geest, S. ( 2014) Development, content validity and inter-rater reliability testing of the Chronic Illness Management Implementation - Building Research Initiative Group: Chronic Illness Management and Adherence in Transplantation: an instrument to assess the level of chronic illness management implemented in solid organ transplant programs. International Journal of Care Pathways 17( 1-2), 59-71.

Bissonnette, J., Woodend, K., Davies, B., Stacey, D. \& Knoll, G.A. ( 2013) Evaluation of a collaborative chronic care approach to improve outcomes in kidney transplant recipients. Clinical Transplantation 27( 2), 232- 238 .

Bodenheimer, T., Wagner, E.H. \& Grumbach, K. ( 2002) Improving primary care for patients with chronic illness. JAMA 288( 14), 1775- 1779.

Botha, P., Peaston, R., White, K., Forty, J., Dark, J.H. \& Parry, G. ( 2008) Smoking after cardiac transplantation. American Journal of Transplantation: Official Journal of the American Society of Transplantation and the American Society of Transplant Surgeons 8( 4), 866- 871.

Braith, R.W., Schofield, R.S., Hill, J.A., Casey, D.P. \& Pierce, G.L. ( 2008) Exercise training attenuates progressive decline in brachial artery reactivity in heart transplant recipients. The Journal of Heart and Lung Transplantation: The Official Publication of the International Society for Heart Transplantation 27( 1), 52- 59 .

Bronfenbrenner, U. ( 1977) Toward an experimental ecology of human development. American Psychologist 32 (7), 513-531.

Bronfenbrenner, U. ( 1980) The Ecology of Human Development. Experiments by Nature and Design. Harvard University Press, Cambridge, MA.

Bruin, S.R., Heijink, R., Lemmens, L.C., Struijs, J.N. \& Baan, C.A. ( 2011) Impact of disease management programs on healthcare expenditures for patients with diabetes, depression, heart failure or chronic obstructive pulmonary disease: a systematic review of the literature. Health Policy 101( 2), 105- 121.

Bruin, S.R., Versnel, N., Lemmens, L.C., Molema, C.C., Schellevis, F.G., Nijpels, G. \& Baan, C.A. ( 2012) Comprehensive care programs for patients with multiple chronic conditions: a systematic literature review. Health Policy 107( 2-3), 108- 145.

Busse, R., Blümel, M., Scheller-Kreinsen, D. \& Zentner, A. ( 2010) Tackling Chronic Diseases in Europe. Strategies, Interventions and Challenges. The European Observatory on Health Systems and Policies, Brussels.

Butler, J.A., Peveler, R.C., Roderick, P., Smith, P.W., Horne, R. \& Mason, J.C. ( 2004) Modifiable risk factors for non-adherence to immunosuppressants in renal transplant recipients: a cross-sectional study. Nephrology, Dialysis, Transplantation 19( 12), 3144-3149.

Chisholm, M.A., Williamson, G.M., Lance, C.E. \& Mulloy, L.L. ( 2007) Predicting adherence to immunosuppressant therapy: a prospective analysis of the theory of planned behaviour. Nephrology, Dialysis, Transplantation 22( 8), 2339-2348.

Coleman, K., Austin, B.T., Brach, C. \& Wagner, E.H. ( 2009) Evidence on the Chronic Care Model in the new millennium. Health Affairs (Millwood) 28( 1), 75- 85.

Curtil, A., Robin, J., Tronc, F., Ninet, J., Boissonnat, P. \& Champsaur, G. ( 1997) Malignant neoplasms following cardiac transplantation. European Journal of Cardio-thoracic Surgery: Official Journal of the European Association for Cardio-thoracic Surgery 12( 1), 101- 106.

De Bleser, L., Dobbels, F., Berben, L., Vanhaecke, J., Verleden, G., Nevens, F. \& Geest, S. ( 2011) The spectrum of nonadherence with medication in heart, liver, and lung tranplant patients assessed in various ways. Transplant International: Official Journal of the European Society for Organ Transplantation 24( 9), 882-891.

De Geest, S., Dobbels, F., Martin, S., Willems, K. \& Vanhaecke, J. ( 2000) Clinical risk associated with appointment noncompliance in heart transplant recipients. Progress in Transplantation 10, 162- 168.

De Geest, S., Dobbels, F., Fluri, C., Paris, W. \& Troosters, T. ( 2005) Adherence to the therapeutic regimen in heart, lung, and heart-lung transplant recipients. Journal of Cardiovascular Nursing 20( 5 Suppl), S88S98.

De Geest, S., Denhaerynck, K. \& Dobbels, F. ( 2011) Clinical and economic consequences of non-adherence to immunosppressive drugs in adult solid organ transplantation. In International Transplantation Updates ( J.M. Grinyó, ed.), Permanyer Publications, Barcelona, pp. 63-81.

Denhaerynck, K., Abraham, I., Gourley, G., Drent, G., Vleeschouwer, P., Papajcik, D., Lince, E. \& Geest, S. ( 2003) Validity testing of the Long-Term Medication Behavior Self-Efficacy Scale. Journal of Nursing Measurement 11(3), 267-282. 
Denhaerynck, K., Steiger, J., Bock, A., Schafer-Keller, P., Kofer, S., Thannberger, N. \& Geest, S. ( 2007) Prevalence and risk factors of non-adherence with immunosuppressive medication in kidney transplant patients. American Journal of Transplantation 7( 1), 108- 116.

Dew, M.A., Roth, L.H., Thompson, M.E., Kormos, R.L. \& Griffith, B.P. ( 1996) Medical compliance and its predictors in the first year after heart transplantation. Journal of Heart and Lung Transplantation 15( 6), 631- 645 .

Dew, M.A., Kormos, R.L., Roth, L.H., Murali, S., DiMartini, A. \& Griffith, B.P. ( 1999) Early posttransplant medical compliance and mental health predict physical morbidity and mortality one to three years after heart transplantation. Journal of Heart and Lung Transplantation 18( 6), 549- 562.

Dew, M.A., DiMartini, A.F., De Vito Dabbs, A., Myaskovsky, L., Steel, J., Unruh, M., Switzer, G.E., Zomak, R., Kormos, R.L. \& Greenhouse, J.B. ( 2007) Rates and risk factors for nonadherence to the medical regimen after adult solid organ transplantation. Transplantation 83( 7), 858-873.

Dew, M.A., Dimartini, A.F., De Vito Dabbs, A., Zomak, R., De Geest, S., Dobbels, F., Myaskovsky, L., Switzer, G.E., Unruh, M., Steel, J.L., Kormos, R.L. \& McCurry, K.R. ( 2008) Adherence to the medical regimen during the first two years after lung transplantation. Transplantation 85( 2), 193- 202.

Dobbels, F., Geest, S., Cleemput, J., Droogne, W. \& Vanhaecke, J. ( 2004) Effect of late medication noncompliance on outcome after heart transplantation: a 5-year follow-up. Journal of Heart and Lung Transplantation 23( 11), 1245- 1251.

Dobbels, F., Vanhaecke, J., Desmyttere, A., Dupont, L., Nevens, F. \& Geest, S. ( 2005) Prevalence and correlates of self-reported pretransplant nonadherence with medication in heart, liver, and lung transplant candidates. Transplantation 79( 11), 1588- 1595.

Dobbels, F., Berben, L., Geest, S., Drent, G., Lennerling, A., Whittaker, C. \& Kugler, C. ( 2010) The psychometric properties and practicability of self-report instruments to identify medication nonadherence in adult transplant patients: a systematic review. Transplantation 90( 2), 205-219.

Drewes, H.W., Steuten, L.M., Lemmens, L.C., Baan, C.A., Boshuizen, H.C., Elissen, A.M., Lemmens, K.M., Meeuwissen, J.A. \& Vrijhoef, H.J. ( 2012) The effectiveness of chronic care management for heart failure: meta-regression analyses to explain the heterogeneity in outcomes. Health Services Research 47 ( 5), 1926- 1959.

Ducci, J., Simone, P., Denhaerynck, K., Dobbels, F. \& Geest, S. ( 2013) Correlates of subclinical non adherence to immunosuppression after liver transplantation. Transplant International 26( Suppl 2), 99.

Elder, S.J., Pisoni, R.L., Akizawa, T., Fissell, R., Andreucci, V.E., Fukuhara, S., Kurokawa, K., Rayner, H.C., Furniss, A.L., Port, F.K. \& Saran, R. ( 2008) Sleep quality predicts quality of life and mortality risk in haemodialysis patients: results from the Dialysis Outcomes and Practice Patterns Study (DOPPS). Nephrology, Dialysis, Transplantation: Official Publication of the European Dialysis and Transplant Association - European Renal Association 23( 3), 998- 1004.

Epping-Jordan, J.E., Pruitt, S.D., Bengoa, R. \& Wagner, E.H. ( 2004) Improving the quality of health care for chronic conditions. Quality \& Safety in Health Care 13( 4), 299- 305.

Evangelista, L., Ter-Galstanyan, A., Moser, D.K. \& Dracup, K. ( 2009) Smoking among women following heart transplantation: should we be concerned? Progress in Cardiovascular Nursing 24( 4), 119- 123.

Feuerstein, I. \& Geller, A.C. ( 2008) Skin cancer education in transplant recipients. Progress in Transplantation, 18( 4), 232-241; quiz 242.

Fishbein, M., Hennessy, M., Yzer, M. \& Douglas, J. ( 2003) Can we explain why some people do and some do not act on their intentions? Psychology, Health and Medicine 8( 1), 3- 18.

Fried, L., Bernardini, J. \& Piraino, B. ( 2001) Charlson comorbidity index as a predictor of outcomes in incident peritoneal dialysis patients. American Journal of Kidney Diseases 37( 2), 337-342.

Gifford, A.L., Bormann, J.E., Shively, M.J., Wright, B.C., Richman, D.D. \& Bozzette, S.A. ( 2000) Predictors of self-reported adherence and plasma HIV concentrations in patients on multidrug antiretroviral regimens. Journal of Acquired Immune Deficiency Syndromes 23( 5), 386- 395.

Gloster, A.T., Rhoades, H.M., Novy, D., Klotsche, J., Senior, A., Kunik, M., Wilson, N. \& Stanley, M.A. ( 2008) Psychometric properties of the Depression Anxiety and Stress Scale-21 in older primary care patients. Journal of Affective Disorders 110( 3), 248-259.

Goldstein, D.J., Austin, J.H., Zuech, N., Williams, D.L., Stoopler, M.B., Michler, R.E. \& Schulman, L.L. ( 1996) Carcinoma of the lung after heart transplantation. Transplantation 62( 6), 772-775.

Greenstein, S. \& Siegal, B. ( 1998) Compliance and noncompliance in patients with a functioning renal transplant: a multicenter study. Transplantation 66( 12), 1718- 1726.

Gugiu, P.C., Coryn, C., Clark, R. \& Kuehn, A. ( 2009) Development and evaluation of the short version of the Patient Assessment of Chronic Illness Care instrument. Chronic Illness 5( 4), 268- 276.

Hall, M.A., Zheng, B., Dugan, E., Camacho, F., Kidd, K.E., Mishra, A. \& Balkrishnan, R. ( 2002) Measuring patients' trust in their primary care providers. Medical Care Research and Review: MCRR 59( 3), 293318. 
Haque Hussain, S.S., Matthews, G., Todd, P.M. \& Chaudhry, A.N. ( 2011) Skin cancer in renal transplant patients. NHS Foundation Trust, Addenbrookes's Hospital.

Hays, R.D., Kallich, J.D., Mapes, D.L., Joel Coons, S., Amin, S. \& Carter, W. ( 1997) Kidney Disease and Quality of Life Short Form (KDQOL-SF). RAND, Santa Monica.

Hermann, T.S., Dall, C.H., Christensen, S.B., Goetze, J.P., Prescott, E. \& Gustafsson, F. ( 2011) Effect of high intensity exercise on peak oxygen uptake and endothelial function in long-term heart transplant recipients. American Journal of Transplantation: Official Journal of the American Society of Transplantation and the American Society of Transplant Surgeons 11( 3), 536-541.

Hill, M.N., Miller, N.H., DeGeest, S. \& American Society of Hypertension Writing G ( 2010) ASH position paper: adherence and persistence with taking medication to control high blood pressure. Journal of Clinical Hypertension (Greenwich), 12( 10), 757- 764.

International Society of Heart and Lung Transplantation ( 2011) Retrieved from www.ishlt.org on 15 January 2014.

Kane, R.L., Priester, R. \& Totten, A.M. ( 2005) Meeting the Challenge of Chronic Illness. Johns Hopkins University Press, Baltimore.

Kidd, K.E. \& Altman, D.G. ( 2000) Adherence in social context. Controlled Clinical Trials 21( 5 Suppl), $184 \mathrm{~S}-187 \mathrm{~S}$.

Lodhi, S.A., Lamb, K.E. \& Meier-Kriesche, H.U. ( 2011) Solid organ allograft survival improvement in the united states: the long-term does not mirror the dramatic short-term success. American Journal of Transplantation 11( 6), 1226-1235.

Lopez, E.P., Rice, C., Weddle, D.O. \& Rahill, G.J. ( 2008) The relationship among cardiovascular risk factors, diet patterns, alcohol consumption, and ethnicity among women aged 50 years and older. Journal of the American Dietetic Association 108( 2), 248- 256.

Marshall, A.L., Smith, B.J., Bauman, A.E. \& Kaur, S. ( 2005) Reliability and validity of a brief physical activity assessment for use by family doctors. British Journal of Sports Medicine 39( 5), 294- 297; discussion 294-7.

Marsicano Ede, O., Fernandes Nda, S., Colugnati, F., Grincenkov, F.R., Fernandes, N.M., Geest, S. \& Sanders-Pinheiro, H. ( 2013) Transcultural adaptation and initial validation of Brazilian-Portuguese version of the Basel assessment of adherence to immunosuppressive medications scale (BAASIS) in kidney transplants. BMC Nephrology 14, 108.

Miller, N.H., Hill, M., Kottke, T. \& Ockene, I.S. ( 1997) The multilevel compliance challenge: recommendations for a call to action. A statement for healthcare professionals. Circulation 95( 4), 10851090.

Moullec, G., Gour-Provencal, G., Bacon, S.L., Campbell, T.S. \& Lavoie, K.L. ( 2012) Efficacy of interventions to improve adherence to inhaled corticosteroids in adult asthmatics: impact of using components of the chronic care model. Respiratory Medicine 106( 9), 1211- 1225.

Nagele, H., Kalmar, P., Rodiger, W. \& Stubbe, H.M. ( 1997) Smoking after heart transplantation: an underestimated hazard? European Journal of Cardio-thoracic Surgery: Official Journal of the European Association for Cardio-thoracic Surgery 12( 1), 70-74.

Nolte, E. \& McKee, M. ( 2008) Caring for People with Chronic Conditions - A Health System Perspective. Open University Press, Berkshire.

Nunes, V., Neilson, J., O'Flynn, N., Calvert, N., Kuntze, S., Smithson, H., Benson, J., Blair, J., Bowser, A., Clyne, W., Crome, P., Haddad, P., Hemingway, S., Horne, R., Johnson, S., Kelly, S., Packham, B., Patel, M. \& Steel, J. ( 2009) Clinical Guidelines and Evidence Review for Medicines Adherence: Involving Patients in Decisions about Prescribed Medicines and Supporting Adherence. National Collaborating Centre for Primary Care and Royal College of General Practitioners, London.

Nuno, R., Coleman, K., Bengoa, R. \& Sauto, R. ( 2012) Integrated care for chronic conditions: the contribution of the ICCC Framework. Health Policy 105( 1), 55- 64.

Osterberg, L. \& Blaschke, T. ( 2005) Adherence to medication. New England Journal of Medicine 353( 5), 487- 497.

Owen, J.E., Bonds, C.L. \& Wellisch, D.K. ( 2006) Psychiatric evaluations of heart transplant candidates: predicting post-transplant hospitalizations, rejection episodes, and survival. Psychosomatics 47( 3), 213222.

Peterson, P.N., Shetterly, S.M., Clarke, C.L., Bekelman, D.B., Chan, P.S., Allen, L.A., Matlock, D.D., Magid, D.J. \& Masoudi, F.A. ( 2011) Health literacy and outcomes among patients with heart failure. JAMA: The Journal of the American Medical Association 305( 16), 1695- 1701.

Pruitt, S.D. \& Epping-Jordan, J.E. ( 2005) Preparing the 21st century global healthcare workforce. BMJ 330( 7492), 637-639.

Russell, C.L., Kilburn, E., Conn, V.S., Libbus, M.K. \& Ashbaugh, C. ( 2003) Medication-taking beliefs of adult renal transplant recipients. Clinical Nurse Specialist CNS, 17( 4), 200-208; quiz 209-30. 
Sabaté, E. ( 2003) Adherence to Long-term Therapies: Evidence for Action. World Health Organization, Geneva.

Schmid-Mohler, G., Thut, M.P., Wuthrich, R.P., Denhaerynck, K. \& Geest, S. ( 2010) Non-adherence to immunosuppressive medication in renal transplant recipients within the scope of the Integrative Model of Behavioral Prediction: a cross-sectional study. Clinical Transplantation 24( 2), 213-222.

Schmidt, A., Pleiner, J., Bayerle-Eder, M., Wiesinger, G.F., Rodler, S., Quittan, M., Mayer, G. \& Wolzt, M. ( 2002) Regular physical exercise improves endothelial function in heart transplant recipients. Clinical Transplantation 16( 2), 137- 143.

Stehlik, J., Edwards, L.B., Kucheryavaya, A.Y., Benden, C., Christie, J.D., Dipchand, A.I., Dobbels, F., Kirk, R., Rahmel, A.O., Hertz, M.I. \& International Society of, H. \& Lung, T ( 2012) The registry of the International Society for Heart and Lung Transplantation: 29th official adult heart transplant report-2012. Journal of Heart and Lung Transplantation 31( 10), 1052- 1064.

Swiss Childhood Cancer Registry. Swiss Childhood Cancer Registry Swiss study on the health of people with cancer, leukemia or tumor in child hood. Retrieved from http://www.kinderkrebsregister.ch/fileadmin/KKR08/uploads/pdf/Fragebogen_Erwachsene.pdf on 15 January 2014.

Swiss Federal Statistical Office ( 2008) Gesundheit und Gesundheitsverhalten in der Schweiz 2007: Schweizerische Gesundheitsbefragung. Swiss Federal Statistical Office, Neuchâtel.

The Transplant360 Task Force. The Identifying Medication Adherence Barriers (IMAB) questionnaire. Retrieved from http://www.transplant360.com/download/professionals/IMAB.pdf?doc=IMAB\&updates=false on 15 January 2014.

Viswanathan, M., Golin, C.E., Jones, C.D., Ashok, M., Blalock, S., Wines, R.C.M., Coker-Schwimmer, E.J.L., Grodensky, C.A., Rosen, D.L., Yuen, A., Sista, P. \& Lohr, K.N. ( 2012a) Closing the Quality Gap: Revisiting the State of the Science (Vol. 4: Medication Adherence Interventions: Comparative Effectiveness). Agency for Healthcare Research and Quality (US), Rockville, MD.

Viswanathan, M., Golin, C.E., Jones, C.D., Ashok, M., Blalock, S.J., Wines, R.C., Coker-Schwimmer, E.J., Rosen, D.L., Sista, P. \& Lohr, K.N. ( 2012b) Interventions to improve adherence to self-administered medications for chronic diseases in the United States: a systematic review. Annals of Internal Medicine 157( 11), 785- 795 .

Westaway, M.S., Rheeder, P., Zyl, D.G. \& Seager, J.R. ( 2003) Interpersonal and organizational dimensions of patient satisfaction: the moderating effects of health status. International Journal for Quality in Health Care 15(4), 337-344.

Wild, D., Grove, A., Martin, M., Eremenco, S., McElroy, S., Verjee-Lorenz, A. \& Erikson, P. ( 2005) Principles of Good Practice for the Translation and Cultural Adaptation Process for Patient-Reported Outcomes (PRO) Measures: report of the ISPOR Task Force for Translation and Cultural Adaptation. Value Health 8( 2), 94- 104.

Wilson, I.B., Schoen, C., Neuman, P., Strollo, M.K., Rogers, W.H., Chang, H. \& Safran, D.G. ( 2007) Physician-patient communication about prescription medication nonadherence: a 50 -state study of America's seniors. Journal of General Internal Medicine 22( 1), 6- 12.

World Medical Organization ( 1996) Declaration of Helsinki. BMJ 313( 7070), 1448-1449.

Yach, D. ( 2002) Innovative Care for Chronic Conditions - Building Blocks for Action. World Health Organization, Geneva.

Zallek, S.N., Redenius, R., Fisk, H., Murphy, C. \& O'Neill, E. ( 2008) A single question as a sleepiness screening tool. Journal of Clinical Sleep Medicine 4( 2), 143- 148.

Zhao, D., Qi, Y., Zheng, Z., Wang, Y., Zhang, X.Y., Li, H.J., Liu, H.H., Zhang, X.T., Du, J. \& Liu, J. ( 2011) Dietary factors associated with hypertension. Nature Reviews. Cardiology 8( 8), 456- 465.

Zwald, F.O., Christenson, L.J., Billingsley, E.M., Zeitouni, N.C., Ratner, D., Bordeaux, J., Patel, M.J., Brown, M.D., Proby, C.M., Euvrard, S., Otley, C.C. \& Stasko, T. ( 2010) Melanoma in solid organ transplant recipients. American Journal of Transplantation: Official Journal of the American Society of Transplantation and the American Society of Transplant Surgeons 10( 5), 1297- 1304. 